\title{
Changes in Tissue Oxygen Saturation in Response to Different Calf Compression Sleeves
}

\author{
T. Dermont, ${ }^{1,2}$ L. Morizot, ${ }^{1}$ M. Bouhaddi, ${ }^{1,3}$ and A. Ménétrier ${ }^{1}$ \\ ${ }^{1}$ EA3920 Marqueurs Pronostiques et Facteurs de Régulations des Pathologies Cardiaques et Vasculaires, \\ Plateforme Exercice Performance Santé Innovation, SFR FED 4234, Université de Franche-Comté, Besançon, France \\ ${ }^{2}$ Université Savoie Mont Blanc, Chambéry, France \\ ${ }^{3}$ Physiologie-Exploration Fonctionnelles, CHRU de Besançon, France
}

Correspondence should be addressed to A. Ménétrier; arnaud.menetrier@laposte.net

Received 6 July 2015; Accepted 18 August 2015

Academic Editor: Adrian W. Midgley

Copyright ( $) 2015$ T. Dermont et al. This is an open access article distributed under the Creative Commons Attribution License, which permits unrestricted use, distribution, and reproduction in any medium, provided the original work is properly cited.

\begin{abstract}
Aim. The purpose was to examine the changes in tissue oxygen saturation $\left(\mathrm{StO}_{2}\right)$ in response to the application of different commercially available calf compression sleeves. Methods. Eight subjects came to the laboratory to complete a session in seated position including $10 \mathrm{~min}$ of quiet rest followed by $3 \mathrm{~min}$ measuring calf $\mathrm{StO}_{2}$ without compression sleeves and then alternating of 3 min of passive rest and 3 min measuring $\mathrm{StO}_{2}$ with calf compression sleeves. A total of 15 different commercially available compression sleeves were studied in a randomized order. Calf $\mathrm{StO}_{2}$ was recorded using near-infrared spectroscopy. Results. StO $\mathrm{O}_{2}$ was significantly increased with all compression sleeves $(p<0.05)$ compared with no compression (from $+6.9 \%$ for the least effective to $+22.6 \%$ for the most effective). Large differences were observed between compression sleeves $(p<0.05)$. StO $\mathrm{t}_{2}$ was positively correlated with compression pressure $(p<0.05 ; r=0.84)$. Conclusion. This study shows that wearing compression sleeves from various brands differently affects tissue oxygen saturation. Differences were linked to the compression pressure: higher compression pressures were associated with higher $\mathrm{StO}_{2}$.
\end{abstract}

\section{Introduction}

Compression therapy is used for the treatment of venous pathologies such as deep vein thrombosis and chronicvenous insufficiency [1]. The application of the external pressure on the lower limbs acts to compress the veins thus reducing their diameter [2]. In consequence the velocity increases [2], which in turn encourages the return of blood to the heart and reduces pooling [2]. Many studies have demonstrated an increase in mean deep venous velocity, reduced venous pooling, and an improved venous return in patients who wore graduated compression stockings [35]. The use of compression garments in sport is becoming increasingly popular due to claims that they can improve recovery from exercise [6], by exerting these hemodynamic effects.

Evidence for the efficacy of compression garments in recovery is solid with recent meta-analysis supporting the use of compression to alleviate symptoms associated with fatigue
$[6,7]$. Suggested mechanisms include enhanced venous return and blood flow in passive conditions $[8,9]$ that may aid the removal of metabolic waste $[10,11]$, reduce edema $[12,13]$, and improve muscle oxygenation [14, 15]. However in some cases there is little evidence to support some of the purported benefits and gaps in knowledge are still evident $[16,17]$. The heterogeneity of effects could be explained by the disparity in terms of compression garments in all studies [6, 7]. A consensus regarding the appropriate recommendations is also missing.

For example, findings of French et al. [16] indicate that recovery and regeneration appear unaffected by wearing compression garments for $12 \mathrm{~h}$ after a hard training session compared with passive recovery. However, it should be clearly stated that one limitation of this study is that compression garments used were reported to have an average compression pressure of $12 \mathrm{mmHg}$ at the calf [16]. Indeed venous return and other hemodynamic benefits which may aid recovery were previously described to be significantly improved with 


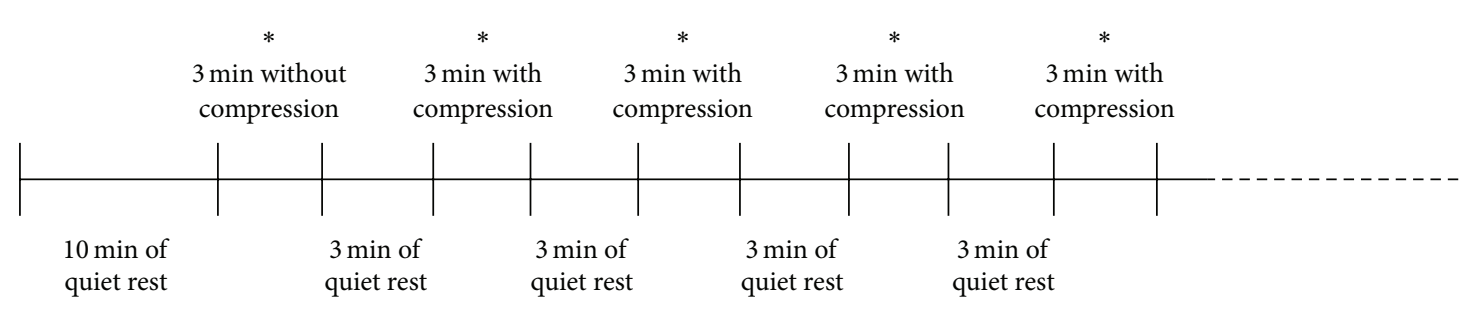

FIGURE 1: Experimental protocol. ${ }^{*} \mathrm{StO}_{2}$ measurements.

a minimum compression pressure of $15-20 \mathrm{mmHg}$ and with a peak for a pressure of around $40 \mathrm{mmHg}[2,18]$.

Some other studies present such limitation $[19,20]$ and recent meta-analysis suggest understanding the discrepancy of results well to focus on the characteristics of compression garments especially compression pressure $[6,7]$. Therefore the aim of the present study was to assess the changes in tissue oxygen saturation $\left(\mathrm{StO}_{2}\right)$ in response to the application of the main commercially available calf compression sleeves. We hypothesized that results may be strongly correlated with the compression pressure. We focused on $\mathrm{StO}_{2}$ because it has been extensively documented as a hemodynamic benefit of compression garments during recovery. It also presents the advantage of being noninvasively measured using nearinfrared spectroscopy (NIRS) [21].

\section{Materials and Methods}

2.1. Participants. Eight healthy subjects (no history of cardiopulmonary disease or medication) were studied (mean $\pm \mathrm{SD}$ : age, $32.4 \pm 4.8$ years; height, $174.5 \pm 1.9 \mathrm{~cm}$; body mass, $66.1 \pm 2.2 \mathrm{~kg}$; calf circumference at larger part: $36.4 \pm$ $0.2 \mathrm{~cm}$ ). They were informed about the procedures and risks associated with participation in the study and all provided their written informed consent prior to participation. The study protocol was approved by the local ethics committee and was in accordance with the Declaration of Helsinki of the World Medical Association with regard to research conduct.

2.2. Study Design. The subjects came to the laboratory (temperature: $20.0 \pm 1.0^{\circ} \mathrm{C}$; humidity: $50 \pm 1.0 \%$ ) to complete a session in seated position including $10 \mathrm{~min}$ of quiet rest followed by $3 \mathrm{~min}$ measuring calf $\mathrm{StO}_{2}$ without compression sleeves and then alternating of $3 \mathrm{~min}$ of quiet rest and $3 \mathrm{~min}$ measuring $\mathrm{StO}_{2}$ with calf compression sleeves. A total of 15 different commercially available compression sleeves were studied in a randomized order (Figure 1).

2.3. Measurements. Using NIRS technique, the InSpectra $\mathrm{StO}_{2}$ Tissue Oxygenation Monitor, Model 650 (Hutchinson, $\mathrm{MN}$, USA), provides continuous noninvasive assessment of $\mathrm{StO}_{2}$ at a maximum depth of $15 \mathrm{~mm}$. The measurement principles of this technology have been described [21] and its accuracy and reproducibility have been previously established [22]. The microcirculatory $\mathrm{StO}_{2}$ assessment is defined as the ratio $\left[\mathrm{HbO}_{2}\right] /\left([\mathrm{Hb}]+\left[\mathrm{HBO}_{2}\right]\right)$ expressed as percent, with $\mathrm{HbO}_{2}$ and $\mathrm{Hb}$ being oxy- and deoxygenated hemoglobin, respectively. The device does not display directly these values. $\mathrm{StO}_{2}$ was measured at the level of the right gastrocnemius muscle, $12 \mathrm{~cm}$ below the fibula head [14]. A transparent film was placed between the skin and the probe to protect it from sweat [23]. $\mathrm{StO}_{2}$ was measured during three minutes without compression and during three minutes with each calf compression sleeve. $\mathrm{StO}_{2}$ values were analyzed with $\mathrm{StO}_{2}$ Researcher's Analysis Software Version 4 (Hutchinson, $\mathrm{MN}$, USA). Only the mean of the last minute of each $3 \mathrm{~min}$ period was considered.

2.4. Compression Sleeves. 15 of main commercially available compression sleeves were studied (Table 1). Their size was chosen according to the individual calf circumference. The pressure of each calf sleeve was measured at the same area as the $\mathrm{StO}_{2}$ measurement using a pneumatic measuring system (Picopress, Microlabitalia, Padua, Italy) [24]. The pressure transducer consists of a flat plastic pressure probe $(5 \mathrm{~cm}$ diameter) that is filled with $2 \mathrm{~mL}$ of air for the pressure measurement. Fluctuations of pressure on this probe are transformed into electronic signals that can be recorded continuously.

2.5. Statistical Analysis. Statistical analyses were performed using SigmaStat software for Windows 3.5 (Systat Software Inc., San Jose, CA, USA). Data are presented as mean \pm SD. A $p$ value $<0.05$ was considered as significant. The normality of distribution was tested using the Kolmogorov-Smirnov test. To assess the effects of the calf compression sleeves, $\mathrm{StO}_{2}$ was analyzed using Repeated Measures ANOVA on Ranks. Student-Newman-Keuls method was used for post hoc pairwise comparisons. Influence of compression pressure on $\mathrm{StO}_{2}$ was assessed using Pearson correlation.

\section{Results}

$\mathrm{StO}_{2}$ recorded with or without compression sleeves is presented in Figure 2. $\mathrm{StO}_{2}$ was significantly increased with all compression sleeves $(p<0.05)$ compared with no compression (from $+6.9 \%$ for A to $+22.6 \%$ for O). Significant differences between compression sleeves were noted and are presented in Figure 3. Influence of compression pressure on $\mathrm{StO}_{2}$ is presented in Figure 3. $\mathrm{StO}_{2}$ was positively correlated with compression pressure $(p<0.05 ; r=0.84)$.

\section{Discussion}

The present study aimed at investigating the changes in $\mathrm{StO}_{2}$ in response to the application of the main commercially 
TABLE 1: Characteristics of calf compression sleeves.

\begin{tabular}{|c|c|c|c|c|c|}
\hline \multirow{2}{*}{ Compression sleeves } & \multirow{2}{*}{ Compression $(\mathrm{mmHg})$} & \multicolumn{3}{|c|}{ Composition (\%) } & \multirow{2}{*}{ Knitting } \\
\hline & & Polyamide & Elastane & Polyester & \\
\hline A & 16.5 & 45.0 & 7.0 & 48.0 & Seamless \\
\hline B & 24.0 & 78.0 & 22.0 & 0 & Seam \\
\hline $\mathrm{C}$ & 23.0 & 80.0 & 20.0 & 0 & Seam \\
\hline $\mathrm{D}$ & 27.5 & 95.0 & 5.0 & 0 & Seamless \\
\hline $\mathrm{E}$ & 30.5 & 77.0 & 23.0 & 0 & Seamless \\
\hline $\mathrm{F}$ & 25.0 & 76.6 & 23.3 & 0.2 & Seamless \\
\hline G & 26.0 & 74.0 & 26.0 & 0 & Seamless \\
\hline $\mathrm{H}$ & 22.5 & 70.0 & 8.0 & 22.0 & Seamless \\
\hline I & 25.0 & 90.0 & 10.0 & 0 & Seamless \\
\hline $\mathrm{J}$ & 31.0 & 79.0 & 21.0 & 0 & Seamless \\
\hline K & 30.5 & 79.0 & 21.0 & 0 & Seamless \\
\hline $\mathrm{L}$ & 36.5 & 65.0 & 35.0 & 0 & Seam \\
\hline M & 37.0 & 47.0 & 30 & 23 & Seamless \\
\hline $\mathrm{N}$ & 39.5 & 60.0 & 25.0 & 15.0 & Seamless \\
\hline $\mathrm{O}$ & 36.5 & 60.0 & 25.0 & 15.0 & Seamless \\
\hline
\end{tabular}

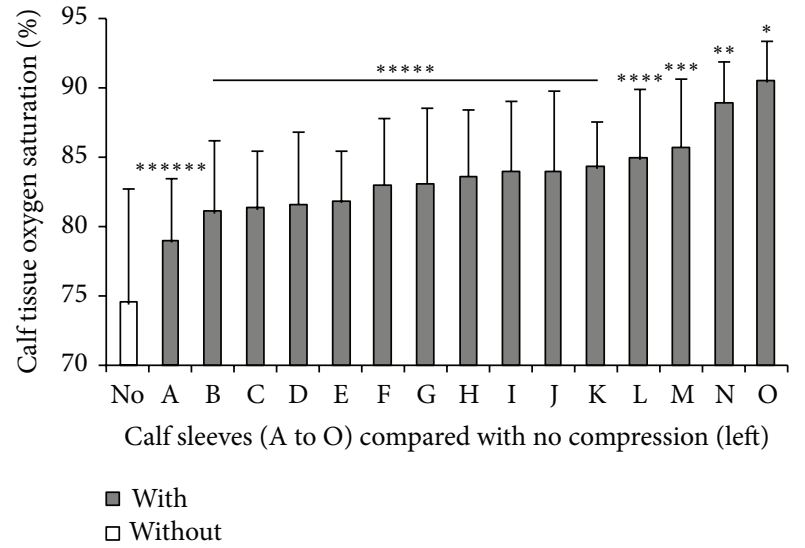

Figure 2: Calf $\mathrm{StO}_{2}$ recorded with or without calf compression sleeves. * Significantly different from all other calf sleeves including no compression. ** Significantly different from $\mathrm{A}$ to $\mathrm{M}$ and no compression. ${ }^{* * *}$ Significantly different from $\mathrm{A}$ to $\mathrm{F}$ and no compression. ${ }^{* * * *}$ Significantly different from A to E and no compression. ${ }^{* * * * *}$ Significantly different from A and no compression. ${ }^{* * * * * *}$ Significantly different from no compression.

available calf compression sleeves. Two major findings have been revealed. (1) Wearing all compression sleeves significantly increased $\mathrm{StO}_{2}$ and (2) the most effective increases of $\mathrm{StO}_{2}$ were correlated with the highest compression pressures. These results confirm our hypothesis and may be explained by several mechanisms.

4.1. Changes in $\mathrm{StO}_{2}$ with Calf Compression Sleeves. Firstly, $\mathrm{StO}_{2}$ increased with calf compression sleeves (from $+6.9 \%$ for A to $+22.6 \%$ for $\mathrm{O}$ ). These results are in accordance with previous works that reported an increase in $\mathrm{StO}_{2}$ with calf compression sleeves before and after running [14] or cycling exercises [25]. This higher $\mathrm{StO}_{2}$ was attributed to the increased

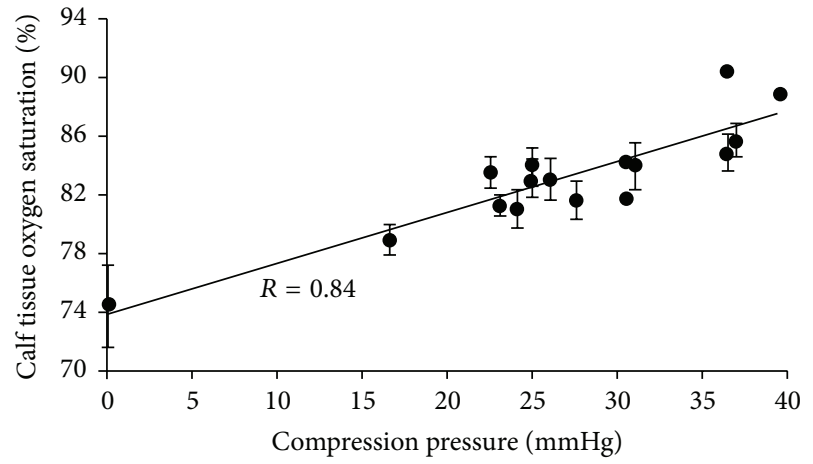

FIgURE 3: Influence of compression pressure $(\mathrm{mmHg})$ on $\mathrm{StO}_{2}$.

muscle flow rate $[8,9]$ and changes in skin blood flow $[26,27]$. Indeed, wearing compression on the lower limbs is known to increase venous return [2], causing venous pressure to decrease [1]. Venous emptying may increase arteriovenous pressure gradient [28], increasing arterial flow rate, oxygen supply, and therefore $\mathrm{StO}_{2}$. The myogenic response may separately contribute to the higher $\mathrm{StO}_{2}$ [9]. As previously described [9], arterial vessels dilate in response to a fall of the transmural vessel pressure gradient. The pressure applied by sleeves is transmitted into the tissue and thus reduces the transmural pressure gradient of the arterial vessels [29]. Finally, changes in skin blood flow must also be considered $[26,27]$. Indeed, $\mathrm{StO}_{2}$ was recorded at a maximum depth of $15 \mathrm{~mm}$, including cutaneous and muscular vessels. Moreover, previous studies suggest that compression sleeves may affect cutaneous $\mathrm{StO}_{2}$ through temperature changes $[14,27]$ and pressure-induced skin vasodilation $[26,30]$.

4.2. Dose-Response: Higher Compression Pressures Were Associated with Higher $\mathrm{StO}_{2}$. This study also revealed that 
increase of calf $\mathrm{StO}_{2}$ with compression sleeves was positively correlated with compression pressure ( $p<0.05 ; r=0.84)$. This finding is in agreement with previous studies suggesting a dose-response of compression pressure on venous hemodynamics including the velocity of venous circulation, venous pump function, or the degree of decrease in edema $[2,3$, 31]. However, the relation between the compression pressure and its effects on hemodynamics is not systematically demonstrated [31-33]. A possible explanation for this lack of relation is that hemodynamics may also be affected by other factors such as pressure gradient $[24,32]$ and elastic properties $[34,35]$. For example, it has been shown that with the same pressure inelastic material is more effective than elastic $[34,35]$. By extension the seamless knitting could be in favor of long lasting effects on $\mathrm{StO}_{2}$ : no fraying and stitch defects making the sleeves loose fit and negatively affecting compression and elastic properties.

4.3. Practical Applications. This study provides support for the hypothesis that wearing compression sleeves from various brands may differently affect recovery, by virtue of their varied effects on $\mathrm{StO}_{2}$. These results contribute to understanding well the large differences reported in recent metaanalysis [6,7] about effects of compression garments during recovery. This study also provides information about relation existing between compression pressure and calf $\mathrm{StO}_{2}$. Since higher compression pressure was associated with higher $\mathrm{StO}_{2}$ this work suggests focusing on compression garments with high pressure level for recovery. However further studies are requested to analyze the balance between effectiveness and comfort [2].

\section{Conclusions}

In conclusion, this study shows that wearing compression sleeves from various brands differently increases tissue oxygen saturation. Differences were linked to the compression pressure: higher compression pressures were associated with higher $\mathrm{StO}_{2}$.

\section{Conflict of Interests}

The authors disclose no conflict of interests.

\section{Acknowledgments}

The authors would like to thank the subjects for their time and enthusiasm. They also thank C. Capitan for technical assistance and F. Ecarnot for editorial assistance.

\section{References}

[1] J. Horner, J. Fernandes, E. Fernandes, and A. N. Nicolaides, "Value of graduated compression stockings in deep venous insufficiency," British Medical Journal, vol. 280, no. 6217, pp. 820-821, 1980.

[2] R. Liu, T. T. Lao, Y. L. Kwok, Y. Li, and M. T.-C. Ying, "Effects of graduated compression stockings with different pressure profiles on lower-limb venous structures and haemodynamics," Advances in Therapy, vol. 25, no. 5, pp. 465-478, 2008.

[3] D. Lawrence and V. V. Kakkar, "Graduated, static, external compression of the lower limb: a physiological assessment," British Journal of Surgery, vol. 67, no. 2, pp. 119-121, 1980.

[4] T. F. O’Donnell Jr., D. A. Rosenthal, A. D. Callow, and B. L. Ledig, "Effect of elastic compression on venous hemodynamics in postphlebitic limbs," Journal of the American Medical Association, vol. 242, no. 25, pp. 2766-2768, 1979.

[5] O. Agu, D. Baker, and A. M. Seifalian, "Effect of graduated compression stockings on limb oxygenation and venous function during exercise in patients with venous insufficiency," Vascular, vol. 12, no. 1, pp. 69-76, 2004.

[6] D.-P. Born, B. Sperlich, and H.-C. Holmberg, "Bringing light into the dark: effects of compression clothing on performance and recovery," International Journal of Sports Physiology and Performance, vol. 8, no. 1, pp. 4-18, 2013.

[7] J. Hill, G. Howatson, K. van Someren, J. Leeder, and C. Pedlar, "Compression garments and recovery from exercise-induced muscle damage: a meta-analysis," British Journal of Sports Medicine, vol. 48, pp. 1340-1346, 2014.

[8] A. Ménétrier, L. Mourot, B. Degano et al., "Effects of three post-exercice recovery treatments on femoral artery blood flow kinetics," The Journal of Sports Medicine and Physical Fitness, vol. 55, no. 4, pp. 258-266, 2015.

[9] R. P. Bochmann, W. Seibel, E. Haase, V. Hietschold, H. Rödel, and A. Deussen, "External compression increases forearm perfusion," Journal of Applied Physiology, vol. 99, no. 6, pp. 23372344, 2005.

[10] A. Ménétrier, J. Pinot, L. Mourot et al., "Effects of recovery using contrast water therapy or compression stockings on subsequent 5-min cycling performance," Journal of Science and Cycling, vol. 2, no. 2, pp. 49-56, 2014.

[11] J.-C. Chatard, D. Atlaoui, J. Farjanel, F. Louisy, D. Rastel, and C.-Y. Guézennec, "Elastic stockings, performance and leg pain recovery in 63-year-old sportsmen," European Journal of Applied Physiology, vol. 93, no. 3, pp. 347-352, 2004.

[12] A. Ménétrier, A. Terrillon, M. Caverot, L. Mourot, and N. Tordi, "Effects of elastic compression during and after the Trail des Forts of Besançon," Kinesitherapie, vol. 14, no. 149, pp. 35-41, 2014.

[13] H. Partsch, J. Winiger, and B. Lun, "Compression stockings reduce occupational leg swelling," Dermatologic Surgery, vol. 30, no. 5, pp. 737-743, 2004.

[14] A. Ménétrier, L. Mourot, M. Bouhaddi, J. Regnard, and N. Tordi, "Compression sleeves increase tissue oxygen saturation but not running performance," International Journal of Sports Medicine, vol. 32, no. 11, pp. 864-868, 2011.

[15] A. Bringard, R. Denis, N. Belluye, and S. Perrey, "Effects of compression tights on calf muscle oxygenation and venous pooling during quiet resting in supine and standing positions," Journal of Sports Medicine and Physical Fitness, vol. 46, no. 4, pp. 548-554, 2006.

[16] D. N. French, K. G. Thompson, S. W. Garland et al., "The effects of contrast bathing and compression therapy on muscular performance," Medicine and Science in Sports and Exercise, vol. 40, no. 7, pp. 1297-1306, 2008.

[17] J. C. Carling, K. Francis, and C. Lorish, "The effects of continuous external compression on delayed-onset muscle soreness (DOMS)," International Journal of Rehabilitation and Health, vol. 1, no. 4, pp. 223-235, 1995. 
[18] G. Mosti, M. L. Iabichella, and H. Partsch, "Compression therapy in mixed ulcers increases venous output and arterial perfusion," Journal of Vascular Surgery, vol. 55, no. 1, pp. 122$128,2012$.

[19] J. C. Chatard, "Elastics bandages, recovery and sport performance," in Proceedings of the Techtextil Symposium, Health and protective textiles, Lyon, France, May 1998.

[20] B. Sperlich, D.-P. Born, K. Kaskinoro, K. K. Kalliokoski, and M. S. Laaksonen, "Squeezing the muscle: compression clothing and muscle metabolism during recovery from high intensity exercise," PLoS ONE, vol. 8, no. 4, Article ID e60923, 2013.

[21] M. Ferrari, L. Mottola, and V. Quaresima, "Principles, techniques, and limitations of near infrared spectroscopy," Canadian Journal of Applied Physiology, vol. 29, no. 4, pp. 463-487, 2004.

[22] V. Quaresima, R. Lepanto, and M. Ferrari, "The use of near infrared spectroscopy in sports medicine," Journal of Sports Medicine and Physical Fitness, vol. 43, no. 1, pp. 1-13, 2003.

[23] Y. N. Bhambhani, "Muscle oxygenation trends during dynamic exercise measured by near infrared spectroscopy," Canadian Journal of Applied Physiology, vol. 29, no. 4, pp. 504-523, 2004.

[24] G. Mosti and H. Partsch, "Occupational leg oedema is more reduced by antigraduated than by graduated stockings," European Journal of Vascular and Endovascular Surgery, vol. 45, no. 5, pp. 523-527, 2013.

[25] B. Boucourt, M. Bouhaddi, L. Mourot, N. Tordi, and A. Ménétrier, "Changes in tissue oxygen saturation with calf compression sleeves-before, during and after a cycling exercise," The Journal of Sports Medicine and Physical Fitness, In press.

[26] P. Abraham, B. Fromy, S. Merzeau, A. Jardel, and J.-L. Saumet, "Dynamics of local pressure-induced cutaneous vasodilation in the human hand," Microvascular Research, vol. 61, no. 1, pp. 122129, 2001.

[27] G. A. Tew, A. D. Ruddock, and J. M. Saxton, "Skin blood flow differentially affects near-infrared spectroscopy-derived measures of muscle oxygen saturation and blood volume at rest and during dynamic leg exercise," European Journal of Applied Physiology, vol. 110, no. 5, pp. 1083-1089, 2010.

[28] M. E. Tschakovsky and R. L. Hughson, "Venous emptying mediates a transient vasodilation in the human forearm," The American Journal of Physiology-Heart and Circulatory Physiology, vol. 279, no. 3, pp. H1007-H1014, 2000.

[29] J. Lundvall and T. Lanne, “Transmission of externally applied negative pressure to the underlying tissue. A study on the upper arm of man," Acta Physiologica Scandinavica, vol. 136, no. 3, pp. 403-409, 1989.

[30] B. Fromy, P. Abraham, and J.-L. Saumet, "Non-nociceptive capsaicin-sensitive nerve terminal stimulation allows for an original vasodilatory reflex in the human skin," Brain Research, vol. 811, no. 1-2, pp. 166-168, 1998.

[31] C. R. Lattimer, M. Azzam, E. Kalodiki, G. C. Makris, and G. Geroulakos, "Compression stockings significantly improve hemodynamic performance in post-thrombotic syndrome irrespective of class or length," Journal of Vascular Surgery, vol. 58, no. 1, pp. 158-165, 2013.

[32] J. Struckmann, H. H. Strange-Vognsen, J. Andersen, and O. Hauch, "Venous muscle pump function in patients with primary lymphoedema: assessment by ambulatory strain gauge plethysmography," British Journal of Surgery, vol. 73, no. 11, pp. 886-887, 1986.
[33] R. A. Weiss and D. Duffy, "Clinical benefits of lightweight compression: reduction of venous-related symptoms by ready-towear lightweight gradient compression hosiery," Dermatologic Surgery, vol. 25, no. 9, pp. 701-704, 1999.

[34] H. Partsch, G. Menzinger, and A. Mostbeck, "Inelastic leg compression is more effective to reduce deep venous refluxes than elastic bandages," Dermatologic Surgery, vol. 25, no. 9, pp. 695-700, 1999.

[35] G. Mosti, V. Mattaliano, and H. Partsch, "Inelastic compression increases venous ejection fraction more than elastic bandages in patients with superficial venous reflux," Phlebology, vol. 23, no. 6, pp. 287-294, 2008. 


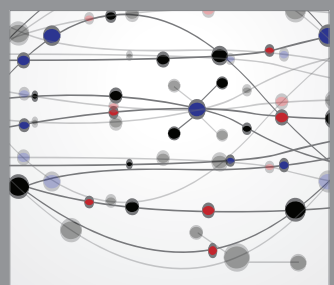

The Scientific World Journal
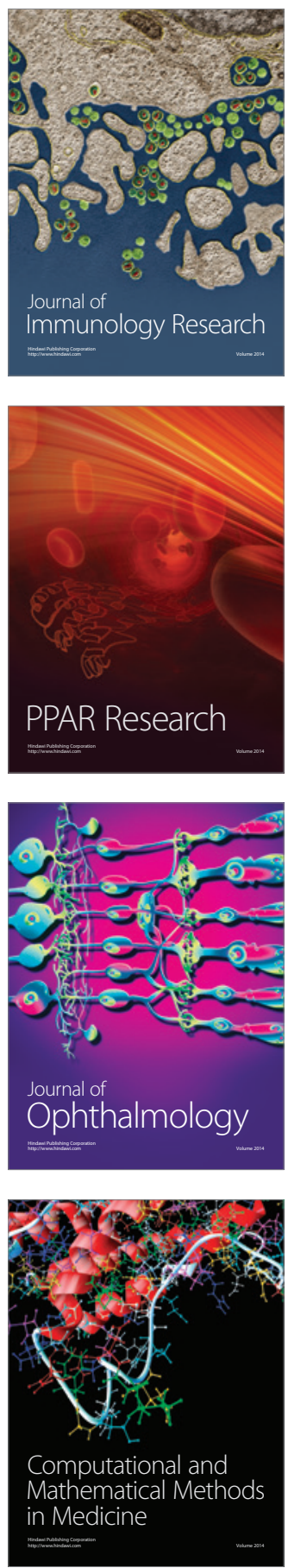

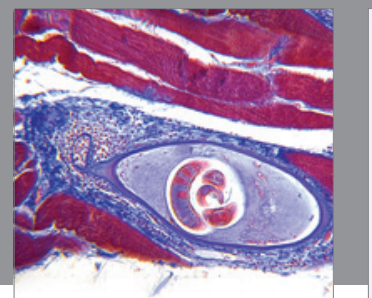

Gastroenterology

Research and Practice
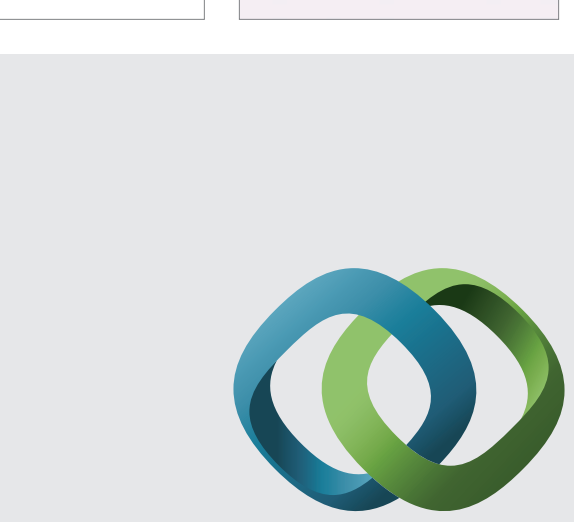

\section{Hindawi}

Submit your manuscripts at

http://www.hindawi.com
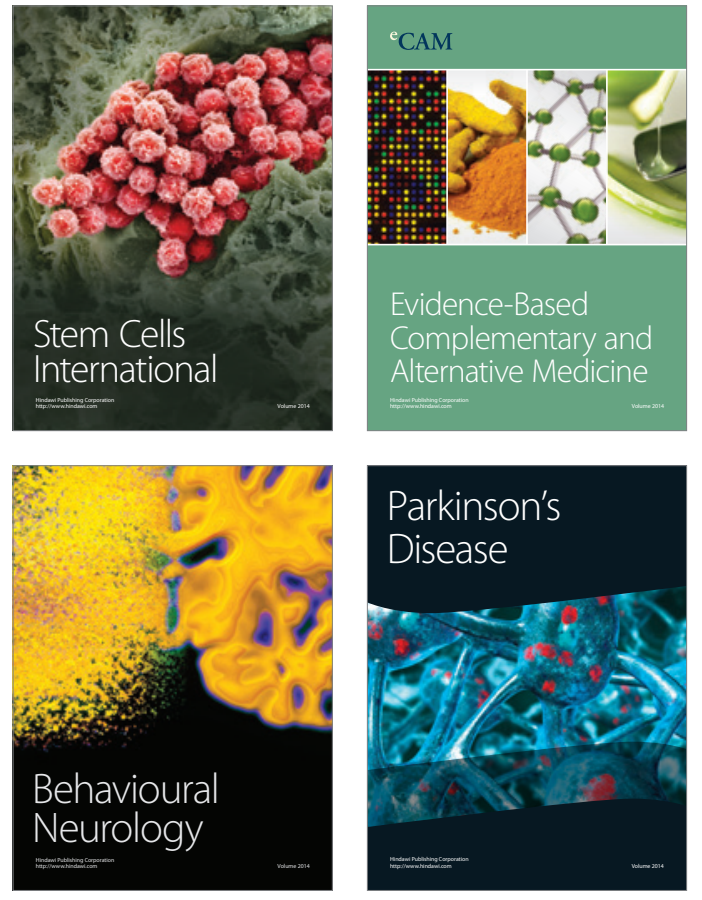
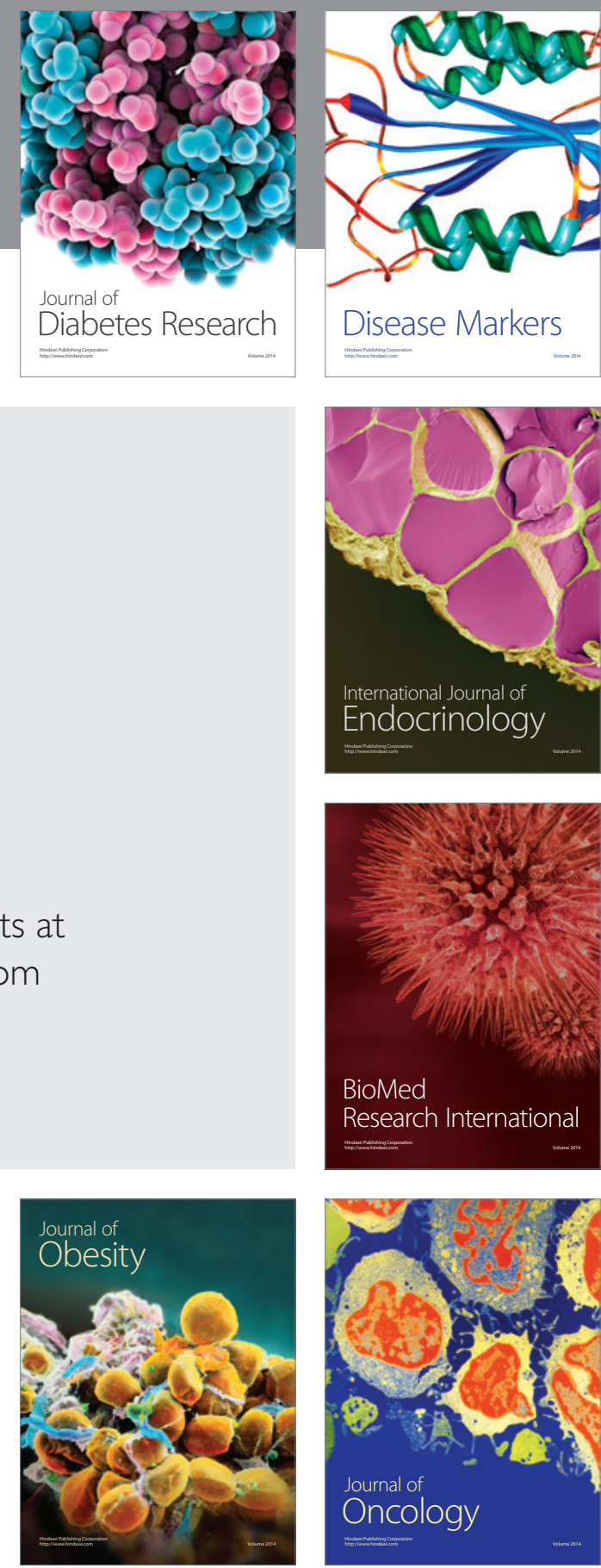

Disease Markers
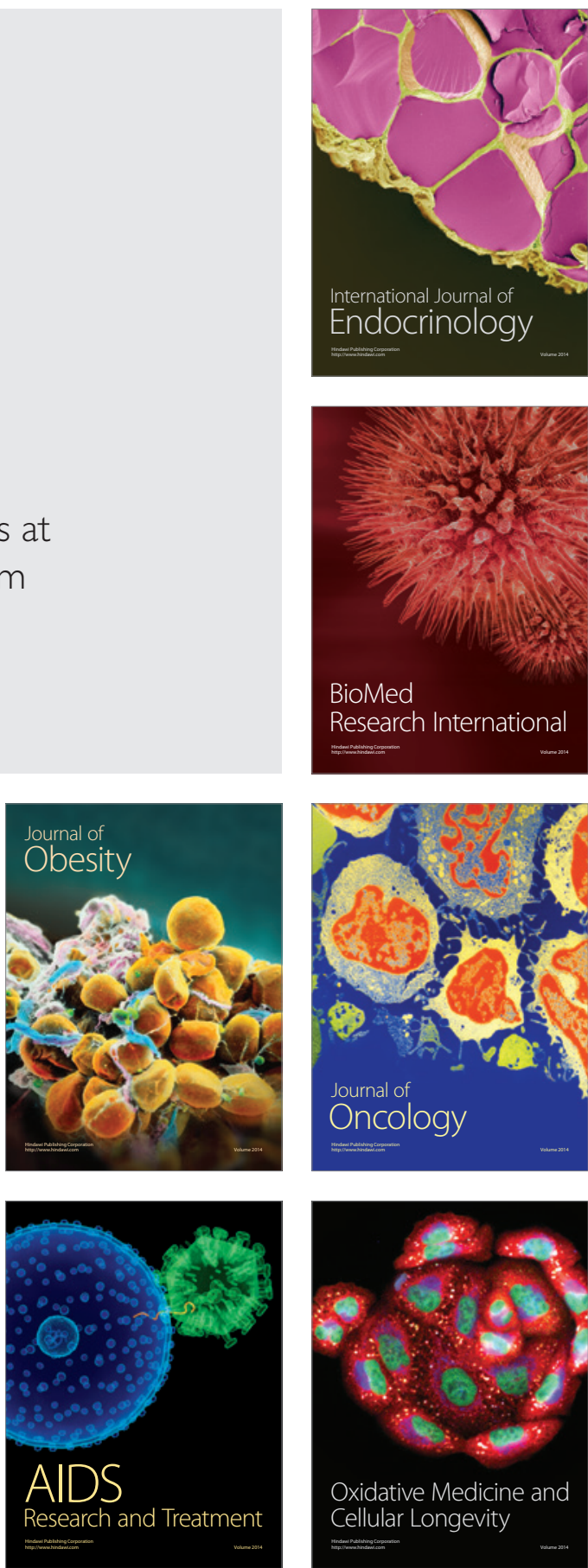